\title{
ДИСКУССИИ
}

DOI: https://doi.org/10.15688/jvolsu2.2021.5.14

UDC 811.133.1'01

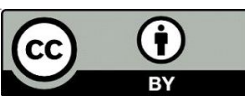

LBC 81.471.1-03

Submitted: 08.02.2021

Accepted: 11.05 .2021

\section{ABSOLUTE PARTICIPIAL CONSTRUCTION THEORY: CONTROVERSIAL ISSUES}

\author{
Yulia V. Bogoyavlenskaya \\ Ural Federal University named after the First President of Russia B.N. Yeltsin, Yekaterinburg, Russia; \\ Petrozavodsk State University, Petrozavodsk, Russia
}

\begin{abstract}
The study focuses on current problems associated with the evolution of absolute participial construction and its linguistic status in the French language. It has been established that, borrowed from classical Latin, the absolute construction with an ablative was accepted to the Old French language, presumably in the $13^{\text {th }}-14^{\text {th }}$ centuries thanks to translations from the Latin language. Widely used in literature, the construction caused disputes among grammarians and only at the beginning of the $20^{\text {th }}$ century it was recognized as normative. In the second part of the article, a review of the Russian and foreign scientific literature is made, the most controversial issues and the author's own position based on corpus data are formulated. The properties inherent in all types of absolute participial constructions are determined: binarity, semantic duality, expression of predominantly temporary, causal meaning or value of an accompanying action, mobility, syntactic optionality in relation to a matrix sentence, the possibility of functioning only as part of a complex sentence. It was revealed that this construction is an economical formal way of expressing a proposition based on a secondary predicative connection. The features of constructions with present participles, past participles and complex past participles are analyzed. The conclusion is made about the need for a differentiated approach to the analysis of these types of absolute structures. The prospect of further studies of linguistic structures is shown.
\end{abstract}

Key words: absolute participial construction, history of the French language, syntax, secondary predicativity, participle.

Citation. Bogoyavlenskaya Yu.V. Absolute Participial Construction Theory: Controversial Issues. Vestnik Volgogradskogo gosudarstvennogo universiteta. Seriya 2. Yazykoznanie [Science Journal of Volgograd State University. Linguistics], 2021, vol. 20, no. 5, pp. 177-190. (in Russian). DOI: https://doi.org/10.15688/jvolsu2.2021.5.14

УДК 811.133 .1 '01

Дата поступления статьи: 08.02.2021

ББК 81.471.1-03

Дата принятия статьи: 11.05.2021

\section{ТЕОРИЯ АБСОЛЮТНОЙ ПРИЧАСТНОЙ КОНСТРУКЦИИ: ДИСКУССИОННЫЕ ВОПРОСЫ}

\author{
Юлия Валерьевна Богоявленская \\ Уральский федеральный университет им. первого Президента России Б.Н. Ельцина, \\ г. Екатеринбург, Россия; \\ Петрозаводский государственный университет, г. Петрозаводск, Россия
}

\begin{abstract}
Аннотация. Исследование посвящено актуальным вопросам, связанным с эволюцией абсолютной причастной конструкции и ее лингвистического статуса во французском языке. Установлено, что заимствованная из классической латыни абсолютная конструкция с аблятивом укоренилась в старофранцузском язы-
\end{abstract}


ке предположительно в XIII-XIV вв. благодаря переводам с латинского языка. Широко используемая в литературе, конструкция вызывала споры среди грамматистов и только в начале XX в. была признана нормативной. На основе обзора отечественной и зарубежной научной литературы сформулированы наиболее дискуссионные вопросы и собственная позиция автора, опирающегося на корпусные данные. Определены свойства, присущие всем типам абсолютной причастной конструкции: бинарность, семантическая двойственность, выражение преимущественно временного, причинного значений или значения сопутствующего действия, мобильность, синтаксическая факультативность по отношению к матричному предложению, возможность функционирования только в составе сложного предложения. Выявлено, что данная конструкция представляет собой экономичный формальный способ выражения пропозиции на основе вторичной предикативной связи. Охарактеризованы особенности конструкций с причастиями настоящего, прошедшего и сложного причастия прошедшего времени. Сделан вывод о необходимости дифференцированного подхода к анализу этих видов абсолютных конструкций. Показана перспектива дальнейших исследований в русле лингвистики конструкций.

Ключевые слова: абсолютная причастная конструкция, история французского языка, синтаксис, вторичная предикативность, причастие.

Цитирование. Богоявленская Ю. В. Теория абсолютной причастной конструкции: дискуссионные вопросы // Вестник Волгоградского государственного университета. Серия 2, Языкознание. - 2021. - Т. 20, № 5.-C. 177-190. - DOI: https://doi.org/10.15688/jvolsu2.2021.5.14

\section{Введение}

Абсолютные причастные конструкции грамматическое явление, составляющее неотъемлемую часть синтаксической системы романских, германских, славянских и других языков. Они позволяют разнообразить синтаксический рисунок текста, выступают альтернативой придаточным предложениям, компактно передавая заложенное в них содержание. Конструкции прошли сложный путь эволюции в языках и вызывали среди лингвистов неоднозначные, порой полярные, мнения - от полного неприятия до восхищения их краткостью, живостью и красотой. Споры вокруг их происхождения, лингвистического статуса и многих других вопросов не утихают до сих пор, а потому требуется всесторонний анализ таких конструкций с учетом достижений современной лингвистики.

В научной литературе наблюдается существенное варьирование в использовании терминологии, интерпретации синтаксических, семантических, прагматических и стилистических характеристик абсолютных причастных конструкций, что, по выражению Жака Фейе, анализировавшего систему причастий во французском языке, свидетельствует о глубоком непонимании лингвистами ее сущности. По словам ученого, только тщательный анализ этого лингвистического феномена поможет преодолеть значительные препятствия на пути осмысления значений причастий и их столь богатого потенциала [Feuillet, 1989, p. 9]. С момента констатации этого факта прошло более 30 лет, лингвисты неоднократно обращались к изучению свойств абсолютной причастной конструкции (далее - АПК). Однако до сих пор существует немало дискуссионных вопросов, касающихся прежде всего происхождения конструкции и ее нормативности. Разногласия обнаруживаются при определении статуса конструкции в современном французском языке: одни лингвисты рассматривают ее как обстоятельство «особого типа», другие - как «причастные придаточные» или «абсолютные причастные» предложения. Полемику вызывает вопрос о предикативности АПК.

В рамках предлагаемой статьи мы рассмотрим спорные вопросы теории АПК, обоснуем избранный подход к ее изучению и проведем сопоставительный анализ различных типов конструкции в современном французском языке.

\section{Материал и методы исследования}

Для исследования обозначенных выше вопросов на первом этапе работы мы обратимся к изучению истории конструкции, которая восходит, по мнению многих лингвистов, к латинскому языку, что предопределило ее синтаксические и семантические особенности, стилистические оттенки. Второй этап исследования - анализ «положения дел» в научной литературе, затрагивающей вопросы тео- 
рии АПК. Третий этап работы - анализ языкового материала: 450 конструкций, собранных смешанным способом, под которым мы имеем в виду комбинирование результатов автоматической выборки в корпусах французского языка (смешанный французский корпус Лейпцигского университета, устный корпус заседаний Европарламента и корпус Википедии на платформе Corpus Eye) и обработки текстов вручную, которая дала богатый и ценный материал, не введенный еще в научный обиход. В корпус вошла личная переписка с коллегами из Франции и других франкофонных государств. Собранный массив был пополнен научными и публицистическими текстами, текстами инструкций, учебных пособий, рекомендаций для преподавателей, блогов, новостных сайтов, институциональных и персональных веб-страниц, комментариев к ним, постами социальных сетей, произведениями религиозной и современной художественной литературы (Katherine Pancol, Danniel Pennac, Amélie Notomb, Albertine Sarrazin, Anna Gavalda). Pazнообразие источников необходимо для изучения реального функционирования конструкции в современном французском языке, выхода за рамки художественной литературы, к анализу которой преимущественно обращались исследователи. Собранный материал обрабатывался в системе экспертного анализа «Лингвистика».

\section{Результаты и обсуждение}

\section{Происхождение \\ абсолютной причастной конструкции во французском языке}

Большинство исследователей истории французского языка полагают, что абсолютная конструкция восходит к ablativus absolutus, использовавшемуся в классической латыни [Grevisse, Goosse, 2008; Togeby, 1973]. Как пишут Т.Б. Алисова, Т.А. Репина, М.А. Таривердиева, данный оборот состоял из субъекта в аблятиве, выступающего в роли логического подлежащего (субъекта), и согласованного с ним прилагательного, причастия I, II или герундива и «синтетически» передавал различные обстоятельственные значения: временные, причинные, инструментальные, уступи- тельные, точный смысл которых определялся из контекста. После исчезновения падежных флексий ablativus absolutus превратился в романских языках в «абсолютный причастный оборот», который употреблялся для передачи видо-временного отношения «результативного предшествования». Его отличительная черта также состояла в отсутствии «коррелятивных элементов», соединяющих конструкцию с основным предложением [Алисова, Репина, Таривердиева, 2007, с. 381].

Однако это не единственная точка зрения. Ш. Балли утверждал, что абсолютные конструкции типа L'ennemi vaincu, l'armée se retire (Враг побежден, армия возвращается) восходят не только к ablativus absolutus, но и к сегментации. «Здесь также обнаруживается сочинительное происхождение. Вначале говорили: L'ennemi (est) vaincu; l'armée se retire; в дальнейшем аналогия с такими предложениями, как Maintenant que l'ennemi est vaincu, après la défaite de l'ennemi ... "Теперь, когда враг побежден, после разгрома врага...", вызвала изменение толкования одновременно с изменением интонации. Латинский ablativus absolutus hoste victo "победив врага" служил в качестве вспомогательного средства, особенно в книжном языке, но он не является единственной отправной точкой этого типа» [Балли, 1955, с. 78]. Родство абсолютной причастной конструкции в других романских языках c ablativus absolutus, как правило, также принимается лингвистами (см., например: [Moliner, 2008]).

Исследователи отмечают, что заимствованная из латыни абсолютная конструкция употреблялась в старофранцузском языке (XXIV вв.), хотя их мнения расходятся относительно ее частотности: А. Боннар и К. Ренье утверждают, что она встречалась довольно редко [Bonnard, Regnier, 1991], в то время как $\Phi$. Брюно настаивает на том, что ее частотность в этот период была довольно высока, но преимущественно в переводах, подверженных влиянию латинского языка. Ученый приходит к выводу о том, что регулярно абсолютная конструкция с причастием в других романских языках стала употребляться лишь с XVI в. [Brunot, 1966]. Э. Бурсье полагает, что конструкция вернулась в старофранцузский язык лишь в XIII в. благодаря переводам 
с латинского языка: «...что касается употребления так называемого "ablativus absolutus" в качестве обстоятельства времени, то он был воспринят, по-видимому, ненепосредственно; его вновь ввели около XIII в. переводчики: il me fu demouré douze vins livres, ma nef paiée "у меня осталось 240 ливров по уплате за корабль" (Joinv., 136)» [Бурсье, 2004, с. 315].

До XVI в. латынь была языком администрирования, науки, образования, литературы и оказывала существенное влияние на европейские языки, в том числе на французский, который заимствовал из латыни многие лексические единицы и грамматические формы. В 1539 г. король Франциск I подписал ордонанс, который, помимо прочего, был направлен на закрепление статуса французского языка как единого государственного. Органы управления при составлении документов были обязаны отныне опираться на его парижскую норму вместо латыни. В XVI-XVII вв. латынь уступает место французскому языку во всех областях, даже в науке и высшем образовании, где она еще некоторое время сохраняла свое исключительное положение. Явления, проникшие во французский язык из латинского, теперь часто воспринимаются критически. В частности, К. Вожла в «Remarques sur la langue française» (1647), стремясь к «очищению» и «облагораживанию» французского языка, даже не упоминает абсолютную причастную конструкцию, а относительно cela dit категорически утверждает, что это сочетание некорректно и требуется писать ayant dit cela. Л. де Тамплери критикует употребление причастной конструкции со своим подлежащим и предлагает перестраивать ее, используя глагол в личной форме (см. об этом: [Brunot, 1966]).

Однако в этот период целый ряд ученых заняли противоположную позицию. В «Истории французского языка: от истоков до 1900 года» Ф. Брюно приводит цитаты ученых, восхищающихся красотой и краткостью абсолютной конструкции и рекомендующих ее употребление, поскольку она позволяет сделать предложение емким, живым, ясным и понятным. В частности, по мнению Ля Арп, «этот тип аблатива сейчас приемлем, даже в прозе, так как он делает фразу более быстрой, не нанося вред ее ясности» (цит. по:
[Brunot, 1966, p. 47]). Д. Буур называл конструкцию «самой красивой в языке, поскольку она позволяет выражаться кратко и живо» (цит. по: [Brunot, 1966, p. 49]). Представляется, что именно это свойство и обеспечило конструкции дальнейшую жизнеспособность и востребованность в письменной речи.

В XVIII в. писатели активно использовали конструкцию в своих произведениях, споры по ее поводу среди грамматистов утихли. Однако еще в течение двух веков Французская академия выступала против ее употребления в речи, особенно конструкции с причастием прошедшего времени, настоятельно рекомендуя заменять его на личную форму глагола. Только в начале XX в. конструкция стала восприниматься как естественная для французского языка и приобрела статус нормативной.

\section{Лингвистический статус абсолютной причастной конструкции в современном французском языке}

Прежде всего обратимся к анализу терминологии для обозначения этого явления, затем перейдем к обзору научных трудов и изложим свою позицию.

В российской научной литературе крайне мало работ, посвященных АПК. В трудах преимущественно используется два термина, определяющие подходы к интерпретации конструкции: «абсолютный причастный оборот» и «абсолютная причастная конструкция». При первом подходе «абсолютное» причастие трактуется как часть оборота, имеющего особый синтаксический статус, служит в предложении обстоятельством образа действия, времени, причины (см., например: [Заславская, Алямская, Пашинина, 1978, с. 224; Илия, 1962, с. 273; Кузнецов, 1991, с. 135]). В этих работах хотя и признается некоторая самостоятельность конструкции, но она рассматривается в рамках простого осложненного предложения.

При втором подходе данная структура рассматривается как промежуточная между простым и сложным предложением. В.Г. Гак и Е.Б. Ройзенблит считают, что поскольку причастие является неличной формой глагола, несколько «ущербной» в модальном, временном, видовом и залоговом планах, то пре- 
дикат абсолютного оборота следует называть «вторичным». Однако силы предикативного заряда, типа синтаксической связи с главным предложением (бессоюзное сочинение), интонационного рисунка оказывается достаточно, чтобы назвать такое предложение сочиненным по смежности. Предложения с абсолютным оборотом авторы относят к разряду синтаксических комплексов с бессоюзным паратаксисом. В работе отмечается, что абсолютный оборот не имеет специализированного значения и актуализируется только в контексте [Гак, Ройзенблит, 1965, c. 243]. Близкой позиции придерживаются Е.А. Реферовская, А.К. Васильева, понимающие под абсолютной причастной конструкцией ту, в которой «функция причастия сближается с функцией сказуемого» [Реферовская, Васильева, 1982, с. 276-277].

Е.А. Ванчикова подходит к изучению «абсолютного причастного оборота» (далее АПО) с точки зрения семантико-функционального направления. Его отличие от обычного причастного оборота лингвист видит в том, что причастие имеет «своего носителя предикативного признака». Само причастие рассматривается как носитель вторичного предикативного признака. Признавая наличие самостоятельной пропозиции в АПО, Е.А. Ванчикова считает, что предикативные отношения в нем неполноценны, так как процесс в них выражен неличной формой глагола. Предложение, в которое входит АПО, по мнению автора, «несмотря на полипропозициональность... является простым, а не сложным» [Ванчикова, 2012, с. 97], то есть, по мнению автора, конструкция занимает промежуточное положение между причастной конструкцией и придаточным предложением и является частью простого предложения. Подобный подход реализуется в работе М.С. Нелюбиной, рассматривающей данную конструкцию как причастный оборот с подлежащим, которое не совпадает с подлежащим главного предложения [Нелюбина, 2014, с. 144]. В наших предыдущих работах мы также придерживались этой точки зрения [Богоявленская, Нелюбина, 2015; Нелюбина, Богоявленская, 2016].

Исследуя АПК в статусе промежуточного феномена, Е.А. Алексеева и Д.Э. Передириев рассматривают ее как конструкцию, «самостоятельно формирующую небазисную пропозицию, подобно предикативному ядру придаточного предложения, состоящего из “аналога" подлежащего и “аналога" реляционно-предметного сказуемого (Le soir, les journeaux étalés sur ma table, nous discutons l'affaire...)» [Алексеева, Передириев, 2015, c. 66]. Конструкция квалифицируется как «пониженная в ранге автономная пропозиция» [Алексеева, Передириев, 2015, с. 66].

В научной литературе находит отражение и третий подход к изучению АПК. Так, H.M. Штейнберг прибегает к термину «proposition participale absolue» (абсолютное причастное предложение) [Штейнберг, 1972, c. 226] и предлагает посмотреть на АПК не как на «группу слов» или «особый оборот», а как на особый бессоюзный способ оформления придаточного предложения, имеющего чаще всего значение времени или причины. Глагол в таком предложении воплощается в одной из форм причастия, а подлежащее не совпадает с подлежащим главного предложения [Штейнберг, 1972, с. 70].

Зарубежные лингвисты проявляют заметно более активный интерес к АПК. Необходимо отметить, что на страницах франкоязычных научных журналов активно ведется дискуссия о структурах вторичной предикативности, в число которых попадают абсолютные конструкции различных типов. Например, в 2003 г. вышел специальный номер журнала «Langages», полностью посвященный причастию настоящего времени и герундию. В ряде работ были затронуты и вопросы АПК. Например, Б. Комбетт придерживается мнения, что данные синтаксические образования представляют собой причастные придаточные предложения (subordonnée participiale) и практически приравнивает причастие к личной форме глагола [Combettes, 2003, p. 6]. А. Липски утверждает, что существительное, стоящее перед неличной глагольной формой, нельзя рассматривать как подлежащее, отрицает, что причастие выполняет функцию предиката в данной структуре, хотя признает, что эти формы содержат указание на лицо, подразумевают его. Лингвист видит в данном синтаксическом образовании лишь обстоятельство главного предложения [Lipsky, 2003, p. 72, 76]. Т. Арнавьель видит в конструкции 
вторично-предикативную структуру, включающую существительное или местоимение и причастие, которое выполняет роль центра этого оригинального типа синтагмы, структура которой близка к структуре предложения и к субъектно-предикатным отношениям [Arnavielle, 2003, p. 42]. Как видим, даже в рамках одного выпуска научного журнала конструкция получила неоднозначную трактовку.

В целом, обобщая зарубежный исследовательский опыт, можно сказать, что наибольшие дискуссии вызывает вопрос о грамматическом статусе АПК. Большая часть лингвистов относят АПК к вторично-предикативным структурам, однако характер предикативных отношений оценивается по-разному. Так, Б. Куллан считает, что причастие выступает в роли предиката и образует с именной группой синтаксическое ядро, в котором устанавливаются автономные вторичные предикативные отношения [Kulland, 2008, p. 19]. Д. Эрнандес интерпретирует все французские абсолютные конструкции как дискурсивное проявление вторичной предикации и рассматривает с семантико-прагматической точки зрения как предикативное отношение, интегрированное в предикат более высокого уровня [Hernández, 2010, p. 96]. О. Альмой обращается к изучению форм на -ant, в том числе и к абсолютной конструкции с Participe Présent, в которой эта форма выполняет «чистую» предикативную функцию. Причастие со своим субъектом образует «нексус» (термин, введенный О. Есперсеном и часто используемый в скандинавской лингвистике для обозначения широкого круга вторично-предикативных структур) (см.: [Halmøу, 2008]).

Д. Дени и А. Сансье-Шато признают, что причастие в АПК является носителем предикативного признака, полагают, что в рамках данной конструкции причастие составляет вместе с темой логическое предложение: что-то утверждается (предикат) о чем-либо (субъект) [Denis, Sancier-Château, 1994, p. 393], но авторы отрицают возможность рассмотрения конструкции в качестве грамматически самостоятельного предложения в связи с тем, что причастие лишено категории лица, тогда как глагол в грамматическом предложении должен быть употреблен в личной форме. К этому же мнению склоняется Ж. Тамин-Гард, которая считает, что для построения предложения необходим глагол в личной форме [Tamine-Gardes, 1998].

Р. Вагнер и Ж. Пеншон, изучая конструкцию с причастием прошедшего времени, рассматривают его как отглагольное прилагательное. Исследователи полагают, что причастие не обладает категорией времени, но имеет «хронологическое значение» в зависимости от контекста, в котором оно употреблено. По мнению лингвистов, оно не имеет глагольных признаков, а выражает признак, возникший в результате действия и приписываемый лицу или предмету [Wagner, Pinchon, 1991]. Такую точку зрения можно принять с оговоркой, что это лишь первичная функция причастия. Мы согласны с В.Г. Гаком, что в абсолютной конструкции причастие «выполняет свою вторичную функцию», а именно «заменяет личную форму глагола, следовательно, самостоятельно выражает предикацию» [Гак, 2000, с. 396].

$\mathrm{B}$ «Критической грамматике французского языка» М. Вильме пишет, что подобные конструкции следует рассматривать как обстоятельства [Wilmet, 1997, р. 313]. Как и А. Липски, М. Вильме не признает «подлежащее» конструкции, поскольку причастие не изменяется по лицам, а значит, такое «подлежащее» не может им управлять. Автор обосновывает свою позицию анализом примеров, в которых предлагает трансформировать конструкцию в обстоятельство: Sa nièce arrivant (= à l'arrivée de sa nièce), c'était le feu à la maison.

Таким образом, рядом лингвистов отрицается возможность распространения статуса предложения на абсолютную конструкцию с причастием. Одни исследователи аргументируют свою позицию отсутствием глагольных признаков у причастия, другие - тем, что подлежащее конструкции не является синтаксическим подлежащим, поскольку не управляет лицом глагола. При этом подходе конструкция трактуется как обстоятельство особого типа.

Вступая в дискуссию с теми лингвистами, которые не признают за подлежащим конструкции его функции, К. Мюллер отмечает, что существительное (или местоимение), стоящее перед причастием, является не только 
логическим, но и полноценным синтаксическим подлежащим. Во-первых, оно занимает правостороннюю позицию по отношению к причастию, что отражает фиксированный, прямой порядок слов в современном французском языке; во-вторых, оно не выполняет никаких функций в главном предложении, а следовательно, оно управляется причастием и составляет с ним отдельное предложение. Лингвист иллюстрирует выдвинутое положениепримером La porte étant fermée, Marie s'en alla / * La porte, Marie s'en alla [Muller, 2007, p. 21]. Эти доводы представляются убедительными: подлежащее причастия синтаксически не подчинено никакому элементу в матричном предложении («phrase matrice», «structure matrice») и составляет с ним отдельную синтагму.

В зарубежной лингвистике также оформилась точка зрения, в соответствии с которой АПК трактуется как причастное предложение, чаще всего придаточное. Лингвисты, поддерживающие эту позицию, часто проводят параллели с союзными придаточными предложениями. В частности, М. Рижель, Ж. Пелла, Р. Риуль усматривают в высказывании Le chat parti, les souris dansent семантический эквивалент временного, причинного и условного придаточных: Dès que le chat parti, les souris dansent, Comme le chat parti, les souris dansent, Si le chat parti, les souris dansent [Riegel, Pellat, Rioul, 1994]. А. Фронтье, полагая, что грамматические и логические категории не должны разделяться, настаивает на том, что «причастное предложение является полным предложением (содержит субъект и предикат) и это предложение является придаточным по отношению к главному предложению» [Frontier, 1997, p. 626]. Той жепозиции придерживаются М. Гревисс и А. Гусс [Grevisse, Goosse, 2008].

Полагаем, что такой подход уместен при анализе абсолютных конструкций с причастием прошедшего времени, которые имеют вышеуказанные значения, но неприемлем для конструкций с причастием настоящего времени и сложного причастия прошедшего времени. Ср.:

(1) Cette journée connaît différentes appellations, chacune d'entre elles véhiculant une certaine conception politique (KA. URL: https://
fr.wikipedia.org/wiki/Journée_internationale_ des femmes);

(2) Elle travaillait tellement qu'elle ne s'était pas rendu compte que c'était Noël; son «bienfaiteur» s'étant bien gardé de le lui rappeler de crainte qu'elle ne perde la cadence... (KA. Gavalda A. Ensemble, c'est tout. 2004).

Выделенные комплексы с АПК представляют собой сложные бессоюзные предложения с присоединительными отношениями, на которые невозможно распространить понятие придаточного предложения.

Мы поддерживаем методологическую установку Ф. Муре, который рассматривает абсолютные причастные конструкции как полноценные предложения, состоящие из предиката, выраженного неличной формой глагола, и именной группы в качестве субъекта, и говорит о важности отдельного рассмотрения конструкций с причастием настоящего и прошедшего времени, поскольку степень проявления глагольных признаков в них различна [Mouret, 2011]. Правомерность данного подхода становится очевидной при сопоставлении абсолютных конструкций с Participe présent, Participe passé и Participe passé composé. Этот анализ мы начнем с выявления общих черт, идентифицирующих АПК, затем перейдем к анализу различий.

\section{Сопоставительный анализ типов} абсолютной причастной конструкции

в современном французском языке

Несмотря на чувствительные различия в потенциале причастий, все типы АПК обладают следующими свойствами:

- бинарность: АПК включает два конституента - именную группу (существительное или местоимение, которые могут иметь зависимые слова) и причастие;

- предикативность: АПК представляет собой экономичный формальный способ выражения пропозиции на основе вторичной предикативной связи;

- семантическая двойственность: АПК выражают предикацию, зависимую от матричного предложения, но, присоединяясь к ней бессоюзным способом, они выражают эту связь недифференцированно, что относит весь комплекс к паратаксическим построениям;

- временна́я отнесенность: АПК имеет значение одновременности, закреплен- 
ное за Participe présent, или предшествования действию (Participe passé и Participe passé composé), выраженному глаголом в личной форме в настоящем или в одном из прошедших или будущих времен в матричном предложении;

- выражение (определенно или синкретично) временно́го, каузального значений, значения сопутствующего действия, редко - условного, уступительного значений и значения следствия;

- мобильность: конструкция может предшествовать матричной структуре, следовать за ней или вклиниваться в нее;

- синтаксическая факультативность АПК по отношению к матричной структуре;

- возможность функционирования только в составе сложного предложения: без опорной (матричной) структуры АПК использоваться не может.

Перейдем к анализу конструкций с причастием настоящего времени (Participe présent), в которых наиболее полно раскрываются глагольные свойства: такие конструкции могут употребляться в утвердительной (3) ${ }^{1}$ и отрицательной (4) форме, могут иметь активный, пассивный (5) и местоименный залог (6), могут встраиваться в выделительно-ограничительную конструкцию (7), иметь подлежащее с отрицательным значением, вследствие чего опускается вторая часть отрицания после причастия (8), иметь дополнения, выраженные местоимениями и существительными (9), к причастию, строиться с модальными глаголами разной семантики: pouvoir (10), devoir (11), sembler (12) и др., причастие-сказуемое может быть как глагольным, так и именным (13):

(3) L'été arrivant à grands pas, nous travaillons actuellement sur nos programmes de FLE intensifs de juillet et août (КА. Профессиональная переписка. 17.03.2019);

(4) La manne pétrolière n'étant pas sans inconvénient les autorités se montrent prudentes (French Mixed Corpus. LCC. URL: www.malikounda.com (date of access: 19.09.2006));

(5) L'air dans les villes étant pollué, les produits de ces jardins le sont sans doute aussi (KA. Alter Ego 3+: Guide pédagogique / Guilloux M. [et al.]. 2013);

(6) La mise en ligne est assujettie à une modération, la direction de HAL se réservant le droit de refuser les articles ne correspondant pas aux critères de l'archive (KA. HAL. URL: https://hal.archivesouvertes.fr);

(7) Le Droit n'étant enseigné qu'en Faculté, les étudiants ne le connaissent généralement pas à l'avance (French Mixed Corpus. LCC. URL: www.univubs.fr.txt (date of access: 21.10.2007));

(8) Lundi, calme plat, aucune statistique influente n'étant attendue (French Mixed Corpus. LCC. URL: www.boursier.com (date of access: 11.05.2007));

(9) Charlotte venait de mettre fin à une liaison de deux ans avec un homme marié qui avait rompu au téléphone, sa femme lui soufflant les mots fatals à l'oreille (KA. Pancol K. La valse lente des tortues. 2008);

(10) L'Américain ne pouvant plus esquisser le moindre geste, l'arbitre avait arrêté le match (French Mixed Corpus. LCC. URL: www.sport.france2.fr (date of access: 22.09.2005));

(11) Premièrement, cette réglementation se veut une réponse à la réalité économique actuelle, les entreprises devant réagir à la pression croissante de la concurrence et s'adapter à un marché en continuelle évolution (Corpus Eye. Parliamentary Debates);

(12) La qualification semblant dans la poche, Marseille commettait l'erreur de baisser le pied (French Mixed Corpus. LCC. URL: www.radiofrance.fr (date of access: 21.07.2006));

(13) Les journaux ne sont pas communément considérés comme des 'viviers' de diatopismes, leur emploi y étant en principe peu intense, par rapport aux romans régionalistes traditionnels (KA. Wissner I. Les grands corpus du français moderne : des outils pour étudier le lexique diatopiquement marqué ? / SKY Journal of Linguistics. 2011. № 25).

Отметим, что в конструкциях со сложным причастием прошедшего времени (Participe passé composé) наблюдаются те же свойства, однако проявляются они иногда иначе, чем в конструкциях с причастием настоящего времени. Например, список модальных глаголов, от которых образуются причастия, значительно меньше и встречаются они гораздо реже.

Наиболее слабая и наиболее сложная для анализа позиция у конструкций с причастием прошедшего времени (Participe passé), которое ряд лингвистов считает лишенным глагольных свойств (см., например: [Wagner, Pinchon, 1991]).

Данный вид причастия, действительно, существенно отличается от причастия настоящего времени и сложного причастия прошед- 
шего времени. Все вышеперечисленные свойства, за исключением активного и пассивного залогов и наличия дополнений-существительных, у него не обнаружены.

Специфика причастий прошедшего времени в составе АПК проявляется в следующем: это причастие согласуется с подлежащим в роде и числе (14), употребляется с временными маркерами une fois (15), sitôt (16) и некоторыми другими, допускает, хотя и редко, инверсионный порядок слов (17), может иметь активный (14) или пассивный (18) залог - входящие в состав сложной активной формы непереходного глагола и сложной пассивной формы переходного глагола элементы étant, ayant été могут опускаться, конструкция редуцируется до данного типа (18), в редких случаях может иметь дополнения, выраженные существительными (19):

(14) Et, l'aube venue, quand chacun repartait de son côté, c'était comme s'ils restaient ensemble (KA. Pennac D. L'œil du loup.1984);

(15) Une fois le montage achevé, le mini-film sera mis en ligne sur les sites Internet, téléchargeable sur les réseaux sociaux et envoyé à l'avance à tous les lieux d'enseignement du français en Russie (КА. Профессиональная переписка. 21.10.2019);

(16) Et sitôt sa signature apposée au bas de son nouveau contrat, Ronaldo part pour l'Italie (French Mixed Corpus. LCC. URL: www.cahiersdufootball.net (date of access: 27.09.2007));

(17) On regarde le jeune intellectuel errer dans les rues de Paris, la nuit, une fois refermé le manuel de médecine, quand l'étudiant part faire un tour, sortant "du cliché de sa chambre de bonne mansardée" et se promenant, "seul, toujours", dans cette ville "boule de cristal rougeoyante", où il entend "un coeur comme le sien qui bat" (KA. Simon C. Sur les traces de Frantz Fanon // Le Monde. 2013. 17 July);

(18) Le déjeuner (étant, ayant été) terminé, Philippe rentra chez lui à pied (KA. Pancol K. La valse lente des tortues. 2008);

(19) L'OTAN se retire, l'armée afghane livrée à elle-même (Bobin F. L'OTAN se retire, l'armée afghane livrée à elle-même // Le Monde. 2014. 26 Dec.).

Результаты анализа языкового материала убеждают в правомерности позиции Ф. Муpe, утверждающего, что абсолютные конструкции с причастием прошедшего времени можно рассматривать как безглагольное предложение. Проведя тест с квантификатором tous, автор убедительно доказывает, что именная группа реализуется как полноценное подлежащее [Mouret, 2011, p. 54]. Мы также полагаем, что отсутствие у причастия личных форм не препятствует выполнению функции сказуемого, поскольку лицо задается его подлежащим (существительным, указательным или неопределенным местоимением), соотносимым с 3-м лицом единственного или множественного числа. Более того, в нашем материале встречаются примеры с подлежащими, выраженными личными ударными местоимениями 3-го лица:

(20) Ses parents étaient de modestes baptistes qui ont eu cinq enfants, lui étant le deuxième (Corpus Eye. Wikipedia. 10.11.2020);

(21) Il se moquait de ses robes à 1100 dollars et hésitait à se marier, elle étant «trop parfaite» (Corpus Eye. Wikipedia. 10.11.2020);

(22) Lui s'étant déclaré candidat mi janvier 2018 et elle ayant quitté le cabinet de Macron début Février 2018, ils ont peut être pensé que si on vérifiait sur l'organigramme on verrait rien et que c'était ok! (KA. Twitter. 15.03.2018).

Исследователи также признают, что это подлежащее может быть выражено и личными ударными местоимениями 1-го и 2-го лица: Moi parti, mes manuscrits (trois malles maintenant) restent dans la maison... (пример из [Borillo, 2006]), Vous parti, j'ai perdu le sommeil, la gaité (V. Hugo) (пример из: [Abdoulhamid, 2009]).

Характеризуя конструкцию в целом, полагаем, что нет оснований настаивать на ее «ущербности» или «неполноценности». АПК является результатом синтаксической компрессии, раскрывающей предикативные ресурсы французского языка. Поэтому мы считаем более уместным говорить о некоторой недоопределенности в темпоральном, модальном и залоговом планах в некоторых речевых реализациях АПК. Эта недоопредленность выводится из вербализованного контекста.

Возвращаясь к вопросу о терминологической неопределенности, отметим, что для обозначения изучаемого явления используются термины «абсолютный причастный оборот», «причастная конструкция», «абсолютная причастная конструкция», «причастное предложение», «придаточное причастное предложение», «construction participe absolue 
circonstantielle» (абсолютная причастная обстоятельственная конструкция), «proposition participe (participiale)» (причастное предложение), «subordonnée participiale» (причастное придаточное предложение), "proposition participe absolue» (абсолютное причастное предложение). На наш взгляд, следует признать термин «абсолютный причастный оборот» неудачным, поскольку он соотносится с односубъектными причастными оборотами в составе предложения, привносящими дополнительные признаки атрибутивного или обстоятельственного характера и выполняющими функцию второго или второстепенного сказуемого. Абсолютная же конструкция имеет собственное логическое и синтаксическое подлежащее и выражает «абстрагированное значение сопутствующего действия» [Гак, Ройзенблит, 1965, с. 243]. Полагаем, что термин «конструкция» в этом сочетании более корректен и перспективен, поскольку «конструкциями считаются языковые единицы любого уровня, если они обладают формой и содержанием, так что их элементами могут быть и морфемы, и слова, и предложения» [Лингвистика конструкций, 2010]. В качестве синонима, на наш взгляд, приемлем термин «абсолютное причастное предложение». Как мы уже упоминали, рассматривать АПК в качестве придаточного причастного предложения нельзя, поскольку в данном построении, во-первых, отсутствуют формальные средства связи, позволяющие установить логическое соотношение предложений в составе сложного; вовторых, АПК может иметь не только значения, присущие придаточным предложениям (времени, причины и др.), но и присоединительное значение.

\section{Заключение}

Заимствованная из классической латыни абсолютная конструкция с аблятивом укоренилась в старофранцузском языке предположительно в XIII-XIV вв. благодаря переводам с латинского языка. В связи с утратой падежных флексий в XIV-XV вв. оборот трансформировался в причастную конструкцию с субъектом. Широко используемая в литературе, конструкция вызывала споры сре- ди грамматистов, которые либо проявляли полное ее неприятие и рекомендовали заменять на личную форму глагола, либо восхищались ее емкостью, краткостью и красотой. Лишь в начале XX в. абсолютная конструкция с причастием была признана нормативной во французском языке.

В отечественной и зарубежной научной литературе оформились три основных подхода к изучению АПК в современном французском языке: рассмотрение ее как обстоятельства, как структуры с «особым статусом» (промежуточным между простым и сложным предложением) и как предложения. Последний подход представляется наиболее обоснованным. Результаты анализа языковых данных убеждают в необходимости дифференцированного изучения абсолютных конструкций с причастиями, поскольку они имеют различные характеристики.

Изучение научных трудов и исследовательского материала привело нас к выводу о нетривиальности данного синтаксического комплекса: обладая внешней простотой и стройностью, он вступает в сложные отношения с матричной структурой; ее значение актуализируется только в контексте. На данный момент недостаточно полно описаны свойства компонентов АПК - субъекта причастия, его морфологические особенности и накладываемые конструкцией ограничения, его взаимоотношения с подлежащим матричной структуры, а также самого причастия, его грамматических и семантических свойств, условия мобильности конструкции относительно матричной структуры и др.

Как показал собранный нами материал, сфера употребления конструкции не ограничивается художественной литературой и прессой, на материале которых она традиционно изучалась. Мы установили, что различные виды конструкции довольно частотны в текстах научного и официально-делового стилей, а также в устной речи. Были обнаружены примеры использования форм причастий прошедшего времени в значении действия в будущем, с имплицитным (нулевым) подлежащим и т. д.

АПК содержит постоянные и переменные компоненты, комбинация которых или же наличие (отсутствие) которых влияет на 
транслируемые смыслы, что требует подробного описания и осмысления. Это составляет перспективу исследования, воплощение которой возможно в рамках наиболее перспективного и активно развивающегося в последнее время направления - лингвистики конструкций, исходящего из установки синтаксического равноправия конституентов и необходимости одновременного анализа элементов различных уровней.

\section{ПРИМЕЧАНИЕ}

1 Здесь и далее в тексте в круглых скобках даны ссылки на примеры.

\section{СПИСОК ЛИТЕРАТУРЫ}

Алексеева Е. А., Передириев Д. Э., 2015. Абсолютная конструкция как один из способов предметной квалификации (на материале французского языка) // Вестник Воронежского государственного университета. Серия: Лингвистика и межкультурная коммуникация. № 2. С. $65-69$.

Алисова Т. Б., Репина Т. А., Таривердиева М. А., 2007. Введение в романскую филологию. М. : Высш. шк. 454 с.

Балли Ш., 1955. Общая лингвистика и вопросы французского языка. М. : Иностр. лит. 416 с.

Богоявленская Ю. В., Нелюбина М. С., 2015. Корпусное исследование французских абсолютных причастных конструкций // Гуманитарный вектор. Серия: Филология. Востоковедение. № 4 (44). С. 39-48.

Бурсье Э., 2004. Основы романского языкознания. M. : УРCС. $671 \mathrm{c}$.

Ванчикова Е. А., 2012. Конструкции с двумя разными носителями предикативного признака // Вестник Московского государственного областного университета. Серия: Лингвистика. № 2. C. 94-98.

Гак В. Г., 2000. Теоретическая грамматика французского языка. М. : Добросвет. 832 с.

Гак В. Г., Ройзенблит Е. Б., 1965. Очерки по сопоставительному изучению французского и русского языков. М. : Высш. шк. 378 с.

Заславская П. И., Алямская Н. В., Пашинина Р. А., 1978. Грамматика французского языка. М. : Высш. шк. 323 с.

Илия Л. И., 1962. Синтаксис современного французского языка. М. : Изд-во лит. на иностр. яз. $280 \mathrm{c}$.
Кузнецов В. Г., 1991. Функциональные стили современного французского языка (публицистический и научный). М. : Высш. шк. 159 с.

Лингвистика конструкций, 2010 / отв. ред. Е. В. Рахилина. М. : Азбуковник. 584 с.

Нелюбина М. С., 2014. Французская и испанская абсолютные причастные конструкции в ряду конструкций с неличными формами глагола // Иностранные языки: лингвистические и методические аспекты : сб. науч. тр. Тверь : Твер. гос. ун-т. Вып. 26. С. 142-146.

Нелюбина М. С., Богоявленская Ю. В., 2016. Абсолютная причастная конструкция и смежные явления во французском языке // Вестник Томского государственного университета. Филология. № 3. C. 5-15. DOI: 10.17223/19986645/41/3.

Реферовская Е. А., Васильева А. К., 1982. Теоретическая грамматика современного французского языка. М. : Просвещение. 430 с.

Штейнберг Н. М., 1972. Грамматика французского языка. В 2 ч. Ч. 2. Синтаксис простого и сложного предложения. Л. : Просвещение. 240 с.

Abdoulhamid A., 2009. La subordonnée participiale au participe passé en Français: de la phrase au discours. Paris : Université de la Sorbonne nouvelle-Paris III. 290 p.

Arnavielle T., 2003. Le participe, les formes en -ant : positions et propositions // Langages. № 149. P. 37-54.

Bonnard H., Regnier C., 1991. Petite grammaire de l'ancien français. P. : Magnard. $240 \mathrm{p}$.

Borillo A., 2006. Quelques structures participiales de valeur temporelle en prédication seconde // Travaux Linguistiques du Cerlico: Les formes non finies des verbes. № 19. P. 1-16.

Brunot F., 1966. Histoire d ela langue française, dès origines à 1900. P. : A. Colin. 360 p.

Combettes B., 2003. L'évolution de la forme en -ant : aspects syntaxiques et textuels // Langages. № 149. P. 6-24.

Denis D., Sancier-Château A., 1994. Grammaire du français. P. : Librairie générale française. 608 p.

Feuillet J., 1989. Le système participal français // L'Information grammaticale. №41. P. 6-9. DOI: 10.3406/igram.1989.1998.

Frontier A., 1997. La grammaire du français. P. : Belin. 752p.

Grevisse M., Goosse A., 2008. Le bon usage. 14 éd. Bruxelles : De Boeck, Duclot. 1760 p.

Halmøy O., 2008. Les formes verbales en -ant et la prédication seconde // Travaux de linguistique. № 57. P. 43-62.

Hernández D. G., 2010. La traduction français-espagnol das constructions absolues dans la presse // Synergies Espagne. № 3. P. 95-106.

Kulland B., 2008. Les constructions participiales du francais et leurs traductions norvégiennes 
correspondantes. Masteroppgave : University of Oslo. 93 p.

Lipsky A., 2003. Pour une description sémantique et morpho-syntaxique du participe français et allemand// Langages. № 149. P. 71-85.

Moliner M., 2008. Diccionario de uso español : Edición electrónica. Madrid: Gredos. 1680 p.

Mouret F., 2011. Deux types de constructions absolues dans La Jalousie de Robbe-Grillet // L'Information grammaticale. № 128. P. 51-56.

Muller C., 2007. Participe présent, conjonction et construction du sujet // Travaux Linguistiques du Cerlico : Les formes non finies du verbe 2, no. 19. Rennes : Presses Universitaires de Rennes. P. 19-36.

Riegel M., Pellat J. C., Rioul R., 1994. Grammàire méthodique du français. P. : PUF. 1168 p.

Tamine-Gardes J., 1998. La grammaire : Syntaxe. P. : Armand Collin. 174 p.

Togeby K., 1973. Précis historique de frammaire française. Copenhague : Akademisk Forlag. 260 p.

Wagner R., Pinchon J., 1991. Grammaire du français classique et moderne. P. : Hachette. 687 p.

Wilmet M., 1997. Grammaire critique du français. P. : Hachette. 670 p.

\section{ИСТОЧНИКИ}

$K A$ - картотека автора.

Bobin F. L'OTAN se retire, l'armée afghane livrée à elle-même // Le Monde. 2014. 26 Dec. URL: https://www.lemonde.fr/international/article/ 2014/12/27/1-otan-se-retire-1-armee-afghanelivree-a-elle-meme_4546633_3210.html.

Corpus Eye. Parliamentary Debates. URL: https:// corp.hum.sdu.dk/cqp.fr.html (date of access: 10.11.2020).

French Mixed Corpus. Leipzig Corpora Collection. URL: https://corpora.uni-leipzig.de/en?corpusId= fra_mixed 2012.

Gavalda A. Ensemble, c'est tout. P. : La Dilettante, 2004. $608 \mathrm{p}$.

Guilloux M., Turbide E., Pons S., Dollez C., Rousse M. Alter Ego 3+ : Guide pédagogique. P. : Hachette, 2013. 224 p.

HAL. URL: https://hal.archives-ouvertes.fr (date of access: 06.02.2020)

Pancol K. La valse lente des tortues. P. : Albin Michel, 2008.677 p.

Pennac D. L'œil du loup. P. : Editions Fernand Nathan, $1984.63 \mathrm{p}$.

Simon C. Sur les traces de Frantz Fanon // Le Monde. 2013. 17 July. URL: https://www.lemonde.fr/ culture/article/2013/07/18/sur-les-traces-defrantz-fanon_3449261_3246.html.
Twitter. URL: https://witter.com/tweeter (date of access: 15.03.2018).

Wikipedia. La Journée internationale des femmes. URL: https://fr.wikipedia.org/wiki/Journée_ internationale_des_femmes (date of access: 09.11.2020).

Wissner I. Les grands corpus du français moderne : des outils pour étudier le lexique diatopiquement marqué ? // SKY Journal of Linguistics. 2011. № 25. P. 233-272.

\section{REFERENCES}

Alekseeva E.A., Perediriev D.Ye., 2015. Absolyutnaya konstruktsiya kak odin iz sposobov predmetnoy kvalifikatsii (na materiale francuzskogo yazyka) [Absolute Construction As a Means of Object Qualification (Based on the French Language)]. Vestnik Voronezhskogo gosudarstvennogo universiteta. Seriya: Lingvistika i mezhkulturnaya kommunikatsiya [Proceedings of Voronezh State University. Series: Linguistics and Intercultural Communication], no. 2, pp. 65-69.

Alisova T.B., Repina T.A., Tariverdieva M.A., 2007. Vvedenie v romanskuyu filologiyu [Introduction to Romance Philology]. Moscow, Vysshaya shkola Publ. 454 p.

Balli Sh., 1955. Obshchaya lingvistika $i$ voprosy frantsuzskogo yazyka [General Linguistics and Questions of the French Language]. Moscow, Inostrannaya literatura Publ. $416 \mathrm{p}$.

Bogoyavlenskaya Yu.V., Nelyubina M.S., 2015. Korpusnoye issledovaniye frantsuzskikh absolyutnykh prichastnykh konstruktsiy [Corpus Research of French Absolute Participial Constructions]. Gumanitarnyi vektor. Seriya: Filologiya. Vostokovedeniye [Humanitarian Vector. Philology. Oriental Studies], no. 4 (44), pp. 39-48.

Bursie E., 2004. Osnovy romanskogo yazykoznaniya [Foundations of Romance Linguistics]. Moscow, URSS Publ. $671 \mathrm{p}$.

Vanchikova E.A., 2012. Konstruktsii s dvumya raznymi nositelyami predikativnogo priznaka [Constructions with Two Different Possessors of Predication Sign]. Vestnik Moskovskogo gosudarstvennogo oblastnogo universiteta. Seriya: Lingvistika [Bulletin of the Moscow Region State University. Series: Linguistics], no. 2, pp. 94-98.

Gak V.G., 2000. Teoreticheskaya grammatika frantsuzskogo yazyka [Theoretical Grammar of the French Language]. Moscow, Dobrosvet Publ. 832 p.

Gak V.G., Royzenblit E.B., 1965. Ocherki po sopostavitelnomu izucheniyu frantsuzskogo $i$ 
russkogo yazykov [Essays on the Comparative Study of the French and Russian Languages]. Moscow, Vysshaya shkola Publ. 378 p.

Zaslavskaya P.I., Alyamskaya N.V., Pashinina R.A., 1978. Grammatika frantsuzskogo yazyka [French Grammar]. Moscow, Vysshaya shkola Publ. 323 p.

Iliya L.I., 1962. Sintaksis sovremennogo frantsuzskogo yazyka [Syntax of Modern French]. Moscow, Izd-vo literaturyna inostrannykh yazykakh. 280 p.

Kuznetsov V.G., 1991. Funktsionalnye stili sovremennogo frantsuzskogo yazyka (publitsisticheskiy i nauchnyi) [Functional Styles of Modern French (Publicistic and Scientific)]. Moscow, Vysshaya shkola Publ. 159 p.

Rakhilina E.V., 2010. Lingvistika konstruktsiy [Linguistics of Structures]. Moscow, Azbukovnik Publ. 584 p.

Nelyubina M.S., 2014. Frantsuzskaya i ispanskaya absolutnye prichastnye konstruktsii $\mathrm{v}$ ryadu konstruktsiy s nelichnymi formami glagola [French and Spanish Absolute Participial Constructions with Impersonal Forms of the Verb]. Inostrannye yazyki: lingvisticheskiye $i$ metodicheskiye aspekty: sb. nauch. tr. [Foreign Languages: Linguistic and Methodological Aspects. Collection of Scientific Papers]. Tver, Tverskoy gosudarstvennyy universitet, pp. 143-146.

Nelubina M.S., Bogoyavlenskaya Yu.V., 2016. Absolutnaya prichastnaya konstruktsiya i smezhnye yavleniya vo frantsuzskom yazyke [The Absolute Participial Construction in the French Language and the Adjoining Phenomena]. Vestnik Tomskogo gosudarstvennogo universiteta. Filologiya [Tomsk State University Journal of Philology], no. 3, pp. 5-15. DOI: 10.17223/19986645/41/3.

Referovskaya E.A., Vasilyeva A.K., 1982. Teoreticheskaya grammatika sovremennogo frantsuzskogo yazyka [Theoretical Grammar of Modern French]. Moscow, Prosveshcheniye Publ. $430 \mathrm{p}$.

Shteynberg N.M., 1972. Grammatika frantsuzskogo yazyka. V 2 ch. Ch. 2. Sintaksis prostogo $i$ slozhnogo predlozheniya [French Grammar. In 2 Parts. Part 2. Syntax of Simple and Complex Sentences]. Leningrad, Prosveshchenie Publ. 240 p.

Abdoulhamid A., 2009. La subordonnée participiale au participe passé en Français: de la phrase au discours. Paris, Université de la Sorbonne nouvelle-Paris III. 290 p.

Arnavielle T., 2003. Le participe, les formes en -ant : positions et propositions. Langages, no. 149, pp. 37-54.

Bonnard H., Regnier C., 1991. Petite grammaire de l'ancien français. Paris, Magnard. $240 \mathrm{p}$.

Borillo A., 2006. Quelques structures participiales de valeur temporelle en prédication seconde.
Travaux Linguistiques du Cerlico: Les formes non finies des verbes, no. 19, pp. 1-16.

Brunot F., 1966. Histoire de la langue française, dès origines à 1900. Paris, Armand Colin. 360 p.

Combettes B., 2003. L'évolution de la forme en -ant : aspects syntaxiques et textuels. Langages, no. 149 , pp. 6-24.

Denis D., Sancier-Château A., 1994. Grammaire du français. Paris, Librairie générale française. 608 p.

Feuillet J., 1989. Le système participal français. L'Information grammaticale, no. 41, pp. 6-9. DOI: 10.3406/igram.1989.1998.

Frontier A., 1997. La grammaire du français. Paris, Belin. 752 p.

Grevisse M., GoosseA., 2008. Le bon usage. Bruxelles, De Boeck, Duclot. 1760 p.

Halmøy O., 2008. Les formes verbales en -ant et la prédication seconde. Travaux de linguistique, no. 57, pp. 43-62.

Hernández D.G., 2010. La traduction français-espagnol das constructions absolues dans la presse. Synergies Espagne, no. 3, pp. 95-106.

Kulland B., 2008. Les constructions participiales $d u$ francais et leurs traductions norvégiennes correspondantes. Masteroppgave, University of Oslo. 93 p.

Lipsky A., 2003. Pour une description sémantique et morpho-syntaxique du participe français et allemand. Langages, no. 149, pp. 71-85.

Moliner M., 2008. Diccionario de uso español. Madrid, Gredos. 1680 p.

Mouret F., 2011. Deux types de constructions absolues dans La Jalousie de Robbe-Grillet. L'information grammaticale, no. 128, pp. 51-56.

Muller C., 2007. Participe présent, conjonction et construction du sujet. Travaux Linguistiques du Cerlico: Les formes non finies du verbe 2, no. 19. Rennes, Presses Universitaires de Rennes, pp. 19-36.

Riegel M., Pellat J.C., Rioul R., 1994. Grammaire méthodique du français. Paris, PUF. 1168 p.

Tamine-Gardes J., 1998. La grammaire: Syntaxe. Paris, Armand Collin Publ. 174 p.

Togeby K., 1973. Précis historique de grammaire française. Copenhague, Akademisk Forlag. 260 p.

Wagner R., Pinchon J., 1991. Grammaire du français classique et moderne. Paris, Hachette. 687 p.

Wilmet M., 1997. Grammaire critique du français. Paris, Hachette. 670 p.

\section{SOURCES}

Author's Index Card.

Bobin F. L'OTAN se retire, l'armée afghane livrée à elle-même. Le Monde, 2014, 26 December. URL: https://www.lemonde.fr/international/article/ 
2014/12/27/1-otan-se-retire-1-armee-afghanelivree-a-elle-meme_4546633_3210.html.

Corpus Eye. Parliamentary debates. URL: https://corp. hum.sdu.dk/cqp.fr.html (accessed 10 November 2020).

French Mixed Corpus. Leipzig Corpora Collection. URL: https://corpora.uni-leipzig.de/en?corpusId= fra_mixed_2012.

Gavalda A. Ensemble, c'est tout. Paris, La Dilettante, 2004. 608 p.

Guilloux M., Turbide E., Pons S., Dollez C., Rousse M. Alter Ego 3+: Guide pédagogique. Paris, Hachette Publ., 2013. 224 p.

HAL. URL: https://hal.archives-ouvertes.fr (accessed 6 February 2020).

Pancol K. La valse lente des tortues. Paris, Albin Michel, 2008. 677 p.
Pennac D. L'œil du loup. Paris, Fernand Nathan, 1984. $63 \mathrm{p}$.

Simon C. Sur les traces de Frantz Fanon. Le Monde, 2013, 17 July. URL: https://www.lemonde.fr/ culture/article/2013/07/18/sur-les-traces-defrantz-fanon_3449261_3246.html.

Twitter. URL: https://twitter.com/tweeter (accessed 15 March 2018).

Wikipedia. La Journée internationale des femmes. URL: https://fr.wikipedia.org/wiki/Journée_ internationale_des_femmes (accessed 9 November 2020).

Wissner I. Les grands corpus du français moderne : des outils pour étudier le lexique diatopiquement marqué ? SKY Journal of Linguistics, 2011, no. 25 , pp. $233-272$.

\section{Information About the Author}

Yulia V. Bogoyavlenskaya, Doctor of Sciences (Philology), Professor, Department of Linguistics and Professional Communication in Foreign Languages, Ural Federal University named after the First President of Russia B.N. Yeltsin, Mira St, 19, 620002 Yekaterinburg, Russia; Professor, Department of German and French, Petrozavodsk State University, Prosp. Lenina, 33, 185910 Petrozavodsk, Russia, jvbog@yandex.ru, https://orcid.org/0000-0002-4500-1491

\section{Информация об авторе}

Юлия Валерьевна Богоявленская, доктор филологических наук, профессор кафедры лингвистики и профессиональной коммуникации на иностранных языках, Уральский федеральный университет им. первого Президента России Б.Н. Ельцина, ул. Мира, 19, 620002 г. Екатеринбург, Россия; профессор кафедры немецкого и французского языков, Петрозаводский государственный университет, просп. Ленина, 33, 185910 г. Петрозаводск, Россия, jvbog@yandex.ru, https://orcid.org/0000-0002-4500-1491 